\title{
Tratamento térmico de austêmpera em ferro fundido nodular com adições de nióbio e de cromo
}

\section{Austempering heat treatment in ductile iron with niobium and chromium additions}

Amanda Souza Oliveira Pimentel ${ }^{1}$, Wilson Luiz Guesser ${ }^{1}$,

\footnotetext{
${ }^{1}$ Programa de Pós-Graduação em Ciência e Engenharia de Materiais - PGCEM/UDESC CP: 89.219-710, Joinville, SC e-mail: amandasopimentel@gmail.com; wguesser@tupy.com.br
}

\begin{abstract}
RESUMO
O ferro nodular austemperado (ADI) é indicado para aplicações que demandam alta resistência ao desgaste abrasivo. Uma de suas variações é o CADI (Carbidic Austempered Ductile Iron), que contém em sua microestrutura carbonetos eutéticos livres. A adição de nióbio em ferro nodular também resulta em formação de carbonetos, porém mais duros e estáveis do que os carbonetos presentes em CADI. Macroadições de nióbio em ADI mostram-se promissoras. O presente trabalho estudou a influência da adição de nióbio no tratamento de austêmpera. Cinco composições distintas, ferro nodular sem adições, ferro nodular com cromo e ferro nodular com três adições de nióbio, foram austemperadas a duas temperaturas e cinco tempos distintos. Os valores de teor de austenita retida foram estimados por metalografia. A adição de nióbio provocou a formação de carbonetos primários poligonais, ao passo que a adição de cromo provocou a formação de carbonetos de padrão dendrítico encontrados nas regiões intercelulares. Verificou-se que as adições de nióbio e, mais intensamente a de cromo, aumentam o teor de austenita retida resultante do tratamento de austêmpera, bem como alteram a morfologia da microestrutura ausferrítica.
\end{abstract}

Palavras-chave: austêmpera, ferro fundido nodular, nióbio, cromo.

\begin{abstract}
The austempered ductile iron (ADI) finds applications in abrasive wear resistant parts. CADI (Carbidic Austempered Ductile Iron) is one type of ADI, which contains free eutectic carbides in its microstructure. The addition of niobium in ductile iron also results in the formation of carbides, but harder and more stable than the CADI carbides. Macro additions of niobium are promising. The present work studied the influence of the addition of niobium in the austempering treatment. Five different compositions, ductile iron, ductile iron with chromium and ductile iron with three niobium additions, were austempered at two temperatures for five different times. The retained austenite were estimated by metallography. The addition of niobium caused the formation of primary polygonal carbides while the addition of chromium caused the formation of carbides of dendritic morphology in intercellular regions. The results shows that the additions of niobium and, more intensively, of chromium result in the increasing of the retained austenite content. The additions also affect the morphology of the ausferritic microstructure.
\end{abstract}

Keywords: austempering, ductile cast iron, niobium, chromium.

\section{INTRODUÇÃO}

A notável combinação de propriedades do ferro fundido nodular austemperado (ADI) tem motivado muitas pesquisas na área. Alta resistência à tração, alta dutilidade, resistência ao desgaste e boa tenacidade são propriedades que fazem com que o material seja recomendado para muitas aplicações [1,2]. O ADI tem encontrado aplicação em componentes solicitados ao desgaste, como peças em equipamentos de movimentação de terra e de mineração, componentes automobilísticos, engrenagens e peças estruturais de baixo peso.

A alta resistência ao desgaste em ADI ainda pode ser incrementada pela presença de carbonetos na mi- 
croestrutura. $\mathrm{O}$ ferro fundido nodular austemperado com carbonetos (CADI) é uma variante de ADI com carbonetos livres $\left(\mathrm{Fe}_{3} \mathrm{C}, 1100 \mathrm{HV}\right)$ na microestrutura [1,3]. Entretanto, há algumas desvantagens de sua utilização, como a baixa precisão na obtenção da quantidade desejada de carbonetos e a baixa estabilidade dos mesmos. Neste cenário, o nióbio mostra-se uma alternativa promissora, uma vez que os carbonetos de nióbio são estáveis, de fácil obtenção e alta dureza $(2400 \mathrm{HV})$ [4]. Por outro lado, a adição de nióbio, apesar de não demandar mudanças na rota de fabricação de ferro fundido, apresenta como grande problema a baixa solubilidade de nióbio em ferro [5]. A solidificação inicia-se pela formação de carbonetos de nióbio, de forma que, como ainda não se deu a nucleação de grafita, sequer de austenita, há a tendência à formação de aglomerados de carbonetos de nióbio. Estes, uma vez formados, são de estabilidade muito alta. O resultado é a difícil obtenção de distribuição homogênea de carbonetos de nióbio.

Alguns autores trataram dos efeitos sobre as propriedades mecânicas e tribológicas de macroadições de nióbio em ferro nodular $[4,6,7,8]$, não sendo encontrada melhoria significativa em propriedades mecânicas, exceto para o trabalho de Souza [7], mas verificando-se maior resistência ao desgaste para o material. De fato, melhores propriedades mecânicas não devem ser verificadas, uma vez que a presença de carbonetos estáveis de outros elementos já é reconhecida como sítios de nucleação de trincas [9]. Acerca de macroadições realizadas em ferro nodular e posterior tratamento de austêmpera, maior resistência ao desgaste abrasivo foi confirmada para adição de $1,5 \%$ de nióbio [10].

Alguns elementos de liga são comumente adicionados ao ferro nodular destinado à austêmpera para promover sua austemperabilidade, como $\mathrm{Cu}, \mathrm{Ni}, \mathrm{Mo}$ e $\mathrm{Mn}[11,12]$. Os teores Mo e Mn são, no entanto, controlados para que se evite a formação de carbonetos. Para os elementos nióbio e cromo, é esperada a presença de carbonetos, da mesma forma que se esperam alterações nos parâmetros de austêmpera. As alterações de tais parâmetros decorrem da alteração na força motriz do estágio I da transformação de austêmpera, quando da adição de um elemento [13]. A força motriz é definida como a diferença entre $\mathrm{C} \gamma_{\max }$ (teor de carbono na austenita retida) e $\mathrm{C} \gamma_{0}$ (teor de carbono na austenita precursora). Sendo assim, elementos que reduzam $\mathrm{C} \gamma_{\max }$ e/ou aumentem $\mathrm{C} \gamma_{0}$ devem ser evitados.

Estudos sobre os parâmetros do tratamento de austêmpera de ferros nodulares com adição de nióbio referem-se ao trabalho de ABDULLAH et al. [14] e PADAN [15]. ABDULLAH et al. [14], adicionando $0,254 \%$ de nióbio, estudaram a evolução das propriedades mecânicas conforme o tempo de austêmpera, definindo $1 \mathrm{~h}$ como o tempo ótimo para o tratamento. PADAN [15] estudou o tratamento de austêmpera de ferro com microadição de $0,043 \% \mathrm{Nb}$ combinada à adição de $1,4 \%$ de níquel, verificando pouca variação na transformação ausferrítica pelo tempo a longos tempos de austêmpera (500 minutos). Contudo nenhum dos autores tratou da influência de macroadição de diferentes teores de nióbio no ferro fundido sob tratamento de austêmpera. O objetivo desta pesquisa foi a análise da influência das macroadições de nióbio e cromo em ferro nodular no tratamento de austêmpera por análise de microestrutura ausferrítica resultante de tratamento térmico a diferentes temperaturas e tempos de austêmpera.

\section{MATERIAIS E MÉTODOS}

Produziu-se ferro fundido com três macroadições de nióbio. Também se produziram ferro fundido sem adições e ferro fundido com adição de cromo. A adição de nióbio promove a precipitação de carbonetos em momento anterior à solidificação. Uma composição típica de ferro fundido nodular foi escolhida com adições de $\mathrm{Mo}, \mathrm{Mn}$ e $\mathrm{Cu}$ para assegurar a austemperabilidade, conforme é mostrada na Tabela 1 a composição base para todas as cinco ligas. Produziram-se as amostras em forno industrial. Realizou-se tratamento com magnésio (nodularizante $\% \mathrm{Si}=45 \% / \% \mathrm{Mg}=6 \%$ ) e inoculação. Os materiais foram vazados em moldes de bloco Y $(25,4 \mathrm{~mm})$, de acordo com as dimensões especificadas na norma ASTM A536. Os teores dos elementos de liga (nióbio e cromo) que diferenciam as cinco composições estudadas são para cada liga: Liga 1: ADI $(0 \% \mathrm{Nb}$ e $0 \% \mathrm{Cr})$; Liga 2 : CADI $(1 \% \mathrm{Cr}, 0 \% \mathrm{Nb})$; Liga 3 : ADI $1 \% \mathrm{Nb}(1 \% \mathrm{Nb}$ e $0 \% \mathrm{Cr})$; Liga 4 : ADI $1,8 \% \mathrm{Nb}$ $(1,8 \% \mathrm{Nb}$ e $0 \% \mathrm{Cr})$ e Liga 5 : ADI $2,4 \% \mathrm{Nb}(2,4 \% \mathrm{Nb}$ e $0 \% \mathrm{Cr})$. A microestrutura resultante é composta por matriz ferrítico-perlítica para a maioria das ligas, nódulos de grafita e carbonetos, estes para os ferros ligados a cromo e nióbio. A liga com cromo mostrou-se predominantemente perlítica.

Uma particularidade foi observada para a composição de ligas com Nb, altos teores de Sn. Acredita-se que o elemento tenha sido incorporado como impureza junto ao ferronióbio. Os teores de Sn da liga com nióbio são: $0,006 \% ; 0,008 \%$ e $0,007 \%$ para os ferros nodulares com $1 \% ; 1,8 \%$ e $2,4 \% \mathrm{Nb}$ respectivamente. Para os demais ferros nodulares, o teor de Sn observado foi de $0,006 \%$.

Os carbonetos resultantes da adição de elementos de liga foram analisados por microscopia. Utilizouse o microscópio eletrônico Leo/Zeiss Gemini 1530VP no modo BSD, para a análise de carbonetos de nióbio. 
Para a análise de carbonetos de ferro com cromo, utilizou-se o microscópio ótico de modelo OLYMPUS BX41M-LED, visto que, em microscopia eletrônica, tais carbonetos não podem ser visualizados. Portanto, para o material com cromo, foi necessário o ataque com reagente metalográfico. Escolheu-se o reagente de Behara para que toda a microestrutura fosse escurecida e somente os carbonetos permanecessem claros e em evidência. Para a medição de área percentual de carbonetos, tanto de ferro nodular com cromo, como ferro nodular com nióbio, as amostras foram também atacadas com reagente de Behara e analisadas em microscopia ótica, sob aumento de $200 \mathrm{X}$.

Tabela 1: Composição de liga base de ferro fundido nodular

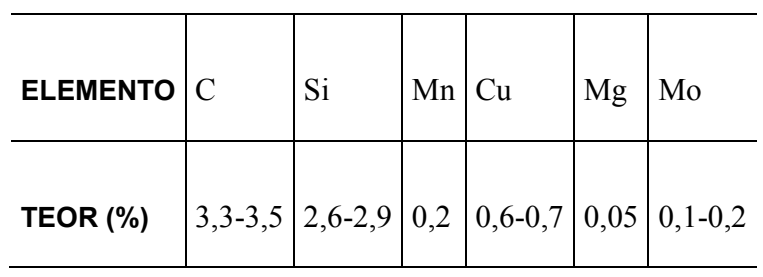

Analisou-se a área percentual de grafita após a fundição de ferro nodular com adição de cromo e com as diferentes adições de nióbio. As amostras como fundidas, ou brutas de fusão, foram lixadas e polidas e então analisadas em microscópio OLYMPUS BX41M-LED. No mínimo 30 imagens foram capturadas de cada amostra sob o aumento de 200X. As imagens foram analisadas fazendo-se uso do software Image Pro Plus e da norma ASTM A-247.

A matriz dos materiais como fundidos foi analisada e as fases presentes foram quantificadas por meio de mesmo microscópio ótico e software. Para tanto, as amostras foram atacadas com Nital 2\%. Sob ataque Nital, os carbonetos permanecem claros como a fase ferrítica. Assim sendo, áreas de carbonetos foram contabilizadas juntamente com áreas de ferrita.

\section{1 Tratamento Térmico}

As temperaturas críticas superior e inferior de austenitização foram estimadas pelas equações de Gerval \& Lacaze [16]. O resultado consta na Tabela 2, onde DI significa "ductile iron". Sendo assim, como se objetiva austenitização completa, temperatura de austenitização a partir de $850^{\circ} \mathrm{C}$ é aplicável aos materiais em estudo. A temperatura de austenitização de $900^{\circ} \mathrm{C}$ foi escolhida para que se evitasse baixo teor de carbono. O tempo de 1 hora foi definido para a completa austentização.

Tabela 2: Temperaturas calculadas crítica superior (TCS) e inferior (TCI) da zona intercrítica.

\begin{tabular}{l|l|l|l|l|l}
\hline MATERIAIS & DI & DI Cr & DI 1\% Nb & DI 1,8\% Nb & DI $\mathbf{2 , 4} \% \mathbf{~ N b}$ \\
\hline TCS $\left({ }^{\circ} \mathrm{C}\right)$ & 823,0 & 811,6 & 821,1 & 818,1 & 819,9 \\
\hline TCI $\left({ }^{\circ} \mathrm{C}\right)$ & 793,9 & 769,8 & 791,9 & 789,1 & 790,8 \\
\hline
\end{tabular}

Segundo a equação de Voigt [17], o teor de carbono na austenita após austentização $\left(\mathrm{C} \gamma_{0}\right)$ é listado na Tabela 3 para os materiais em estudo. Verificou-se teor de carbono ligeiramente maior na austenita para os ferros ligados porque originalmente os ferros apresentam maior teor de carbono pela correção realizada na fundição dos mesmos.

Tabela 3: Teor de carbono na austenita após austenitização segundo equação de Voigt (1984).

\begin{tabular}{l|l|l|l|l|l}
\hline MATERIAIS & DI & DI CR & DI 1\% NB & DI 1,8\% NB & DI 2,4\% NB \\
\hline$\left(\% \mathrm{C}_{\gamma}^{0}\right)$ VOIGT & 0,70 & 0,70 & 0,71 & 0,72 & 0,72 \\
\hline
\end{tabular}

Calculou-se a temperatura de início de transformação martensítica $\left(\mathrm{M}_{\mathrm{s}}\right)$ para as ligas, segundo a equação linear de Andrew [18]. As temperaturas $\mathrm{M}_{\mathrm{s}}$ para cada liga são dadas na Tabela 4, utilizaram-se os teores 
de carbono de austenita precursora conforme os resultados obtidos de Voigt na Tabela 3.

Tabela 4: Temperaturas de início de transformação martensítica $\left(\mathrm{M}_{\mathrm{s}}\right)$ para as ligas em estudo, segundo Andrew (LUI \& ZHAO, 2001).

\begin{tabular}{c|c|c|c|c|c}
\hline MATERIAL & DI & DI CR & DI 1\% NB & DI 1,8\% NB & DI 2,4\% NB \\
\hline $\mathrm{Ms}\left({ }^{\circ} \mathrm{C}\right)$ & 216 & 200 & 212 & 208 & 208 \\
\hline
\end{tabular}

Observa-se que a temperaturas maiores do que $220^{\circ} \mathrm{C}$ não há tendência a ocorrer transformação martensítica. No intuito de se obter matriz de alta resistência mecânica, escolheram-se temperaturas abaixo de $330^{\circ} \mathrm{C}$ para o presente estudo, a saber, $270^{\circ} \mathrm{C}$ e $310^{\circ} \mathrm{C}$. Com isso, há a formação de ausferrita (plaquetas de ferrita com austenita retida) sem precipitação de carbonetos nas agulhas de ferrita.

Portanto, o tratamento térmico consistiu em austenitização a $900^{\circ} \mathrm{C}$ por $1 \mathrm{~h}$ e em tratamento isotérmico de austêmpera que dividiu as amostras em dois grupos: austemperadas a $270^{\circ} \mathrm{C}$ e a $310^{\circ} \mathrm{C}$, ambos os grupos mantidos às temperaturas indicadas por cinco tempos distintos: 30, $70,110,170 \mathrm{e} 230 \mathrm{~min}$. Experimentaram-se todas as composições em todos os tratamentos especificados na Figura 1.

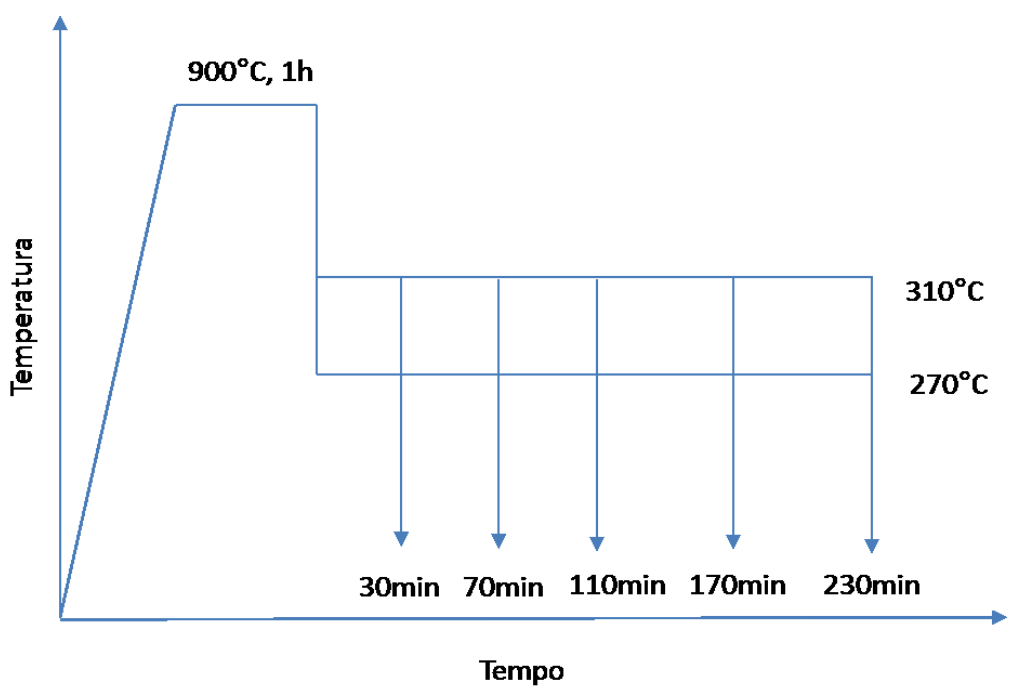

Figura 1: Tratamentos térmicos de austêmpera realizados.

Realizaram-se análises das microestruturas ausferríticas resultantes em microscopia ótica, utilizandose microscópio modelo OLYMPUS BX41M-LED. Realizou-se a quantificação da fase austenita retida, por análise por contraste, fazendo-se uso do software Image Pro Plus. Para que a austenita pudesse ser diferenciada das demais fases, todas as amostras foram lixadas, polidas e então atacadas com reagente de Nital $2 \% \mathrm{e}$ na sequência com metabissulfito de sódio (solução de $10 \mathrm{~g} \mathrm{de} \mathrm{Na}_{2} \mathrm{~S}_{2} \mathrm{O}_{5} \mathrm{em} 100 \mathrm{ml}$ de água destilada). Este ataque confere à austenita coloração clara, enquanto que as demais fases se mostram escuras. Analisaram-se cerca de 15 campos em cada amostra, sob aumento de 1000X. Evitaram-se campos em que grafita ou carbonetos fossem encontrados.

Para as medições de teor de austenita retida, procuraram-se as regiões da matriz livres de manchas de ataque, regiões onde a matriz ausferrítica pudesse ser claramente analisada. Consequentemente, as regiões de austenita residual ou martensita, normalmente regiões intercelulares, foram negligenciadas. A medição por microscopia revela, na verdade, o espaçamento entre as agulhas de ferrita na microestrutura ausferrítica em regiões onde a segregação não tenha alterado a austêmpera. 


\section{RESULTADOS}

Os carbonetos resultantes da adição de nióbio e da adição de cromo são mostrados na Figura 2. Os carbonetos de nióbio mostraram-se poligonais, Figura 2 (a). Segundo a norma VDG [19], os carbonetos de nióbio são de tipo primário de formato poligonal compacto (PC4). A análise da microestrutura de ferros com nióbio revelou distribuição de carbonetos de nióbio satisfatoriamente homogênea. Acerca dos carbonetos de cromo, são classificados como carbonetos eutéticos, também segundo a norma VDG [19], de formato esquelético e arranjo de reticulado aberto (A2), ou seja, apresentam padrão dendrítico. Os carbonetos de cromo são revelados em metalografia sob ataque de reagente Behara, Figura 2 (b). São carbonetos eutéticos do tipo $\mathrm{M}_{3} \mathrm{C}$, onde $\mathrm{M}$ tanto seria $\mathrm{Fe}$ como $\mathrm{Cr}$. Verifica-se que estas regiões com carbonetos se localizam preferencialmente nos contornos das células do eutético austenita + grafita, o que indica que a segregação de cromo, durante a solidificação de austenita + grafita, é importante para a formação destes carbonetos.
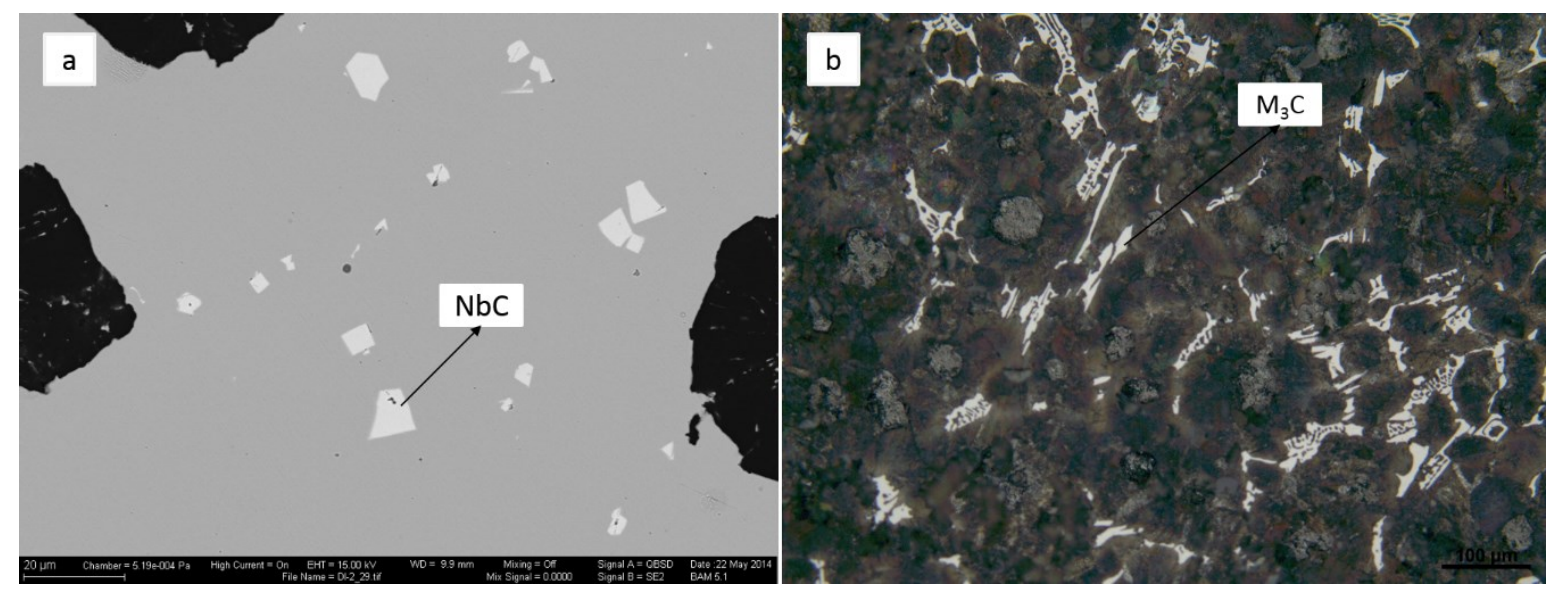

Figura 2: Ferro nodular com 1,8\% de nióbio, carboneto de nióbio indicado na figura (a), microscopia eletrônica; ferro nodular com $1 \%$ de cromo, carboneto indicado na figura (b), ataque de reagente de Behara, microscopia ótica.

Foram medidas as áreas percentuais de carbonetos presentes nas superfícies analisadas metalograficamente das amostras. A Figura 3 mostra a área percentual de carbonetos na superfície, tanto para materiais com nióbio, correspondendo à área de $\mathrm{NbC}$, quanto para o material com cromo, correspondendo a $\mathrm{M}_{3} \mathrm{C}$. Verifica-se que a área de carbonetos aumenta com o aumento do teor de nióbio no ferro nodular.

A área percentual de carbonetos para o cromo é em extremo maior. Faz-se nota de que o teor de cromo em ferro fundido nodular é de $1 \%$, ao passo que os ferros nodulares com nióbio apresentam 1\%, 1,8\% e $2,4 \%$ do elemento. Porém, mesmo contando com maior teor de elemento formador de carboneto, o material com nióbio não apresenta maior área percentual de carboneto. Isto ocorre devido ao fato de os carbonetos de $\mathrm{M} 3 \mathrm{C}$ (de ferro nodular com cromo) conterem cromo e ferro, resultando na formação de maior volume de carbonetos. 


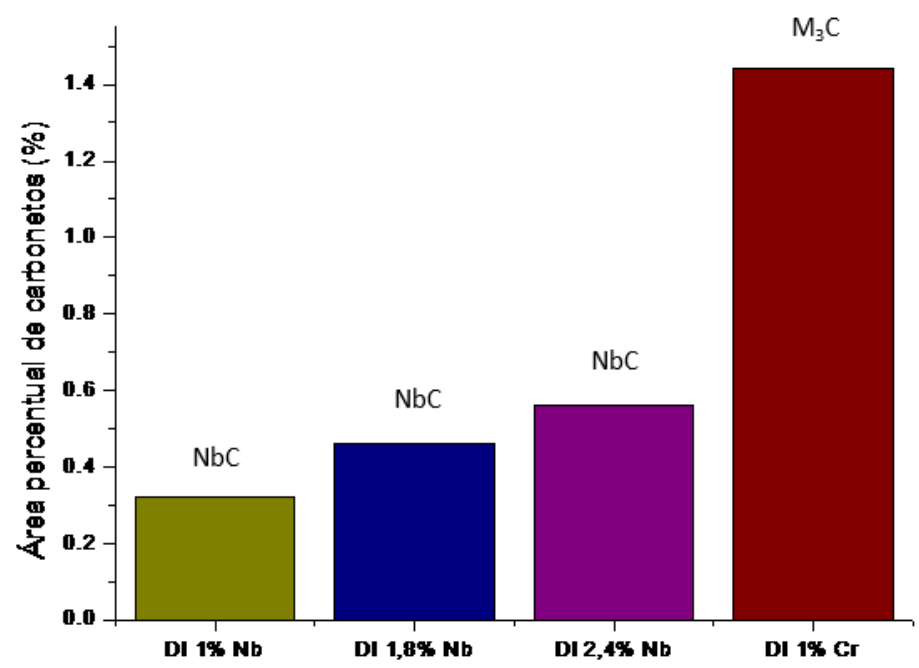

Figura 3: Área percentual de carbonetos em diferentes ferros fundidos nodulares, tipo de carboneto indicado acima das barras.

Os resultados de área percentual de grafita sobre as superfícies das amostras analisadas metalograficamente são mostrados na Tabela 05. Observa-se redução de área percentual para os materiais ligados a cromo e nióbio. Menor precipitação de grafita é esperada para o material com cromo, uma vez que o cromo reduza consideravelmente a atividade do carbono, aumente a quantidade de austenita pró-eutética, e reduza o intervalo DTE. Observa-se para as amostras com nióbio também menor área percentual de grafita. O nióbio também reduz a atividade do carbono. Porém acredita-se que esse efeito seja provocado pelos altos teores de $\mathrm{Sb}$ no material com $\mathrm{Nb}$. O tamanho dos nódulos de grafita de todas as amostras, segundo a norma ASTM-A247, reside entre os tamanhos V e VI. Observa-se nodularidade decrescente com o aumento do teor de $\mathrm{Nb}$. Atribui-se esse fato aos teores de $\mathrm{Sb}$ crescentes com a adição de $\mathrm{Nb}$, uma vez que Sn seja um elemento degenerador de grafita [20].

A tabela 5 também revela os resultados da análise de matriz para amostras como fundidas. Observa-se área percentual de ferrita descendente com o aumento da adição de nióbio. Novamente consideram-se os efeitos de altos teores de Sn para as ligas com Nb. O Sb apresenta reconhecida ação perlitizante [20]. Outro elemento de reconhecida ação perlitizante é o cromo. De fato, o ferro nodular com cromo mostra a menor área percentual de ferrita.

Tabela 5: Dados de análise de nódulos de grafita em amostras como fundidas.

\begin{tabular}{c|c|c|c}
\hline AMOSTRAS & $\begin{array}{c}\text { ÁREA PERCENTUAL DE GRAFI- } \\
\text { TA (\%) }\end{array}$ & NODULARIDADE (\%) & $\begin{array}{c}\text { ÁREA PERCENTUAL DE } \\
\text { FERRITA (\%) }\end{array}$ \\
\hline DI 0 & 8,6 & 98,0 & 22,2 \\
\hline DI Cr & 7,3 & 98,5 & 6,6 \\
\hline DI $1 \mathrm{Nb}$ & 8,3 & 98,0 & 17,3 \\
\hline DI $1,8 \mathrm{Nb}$ & 7,7 & 96,7 & 13,5 \\
\hline DI $2,4 \mathrm{Nb}$ & 8,0 & 90,0 & 13,6 \\
\hline
\end{tabular}

A Figura 4 mostra a evolução do teor de austenita retida com o tempo para tratamento isotérmico a $270^{\circ} \mathrm{C}$. Observa-se um alto pico do teor de austenita retida para valores menores do que 30 minutos para a maioria das composições, exceto para CADI, o qual revela maiores teores de austenita próximo a 100 minutos de austêmpera. Portanto, a partir do primeiro tempo estudado o teor de austenita retida estimado certamente já atingiu seu maior valor e está sendo reduzido com o aumento do tempo. Para os resultados de ferros nodulares com nióbio, encontra-se certa similaridade aos resultados do ADI. No entanto, nota-se que a partir do tempo de 70 minutos o teor de austenita retida estabiliza-se para os materiais com nióbio. 

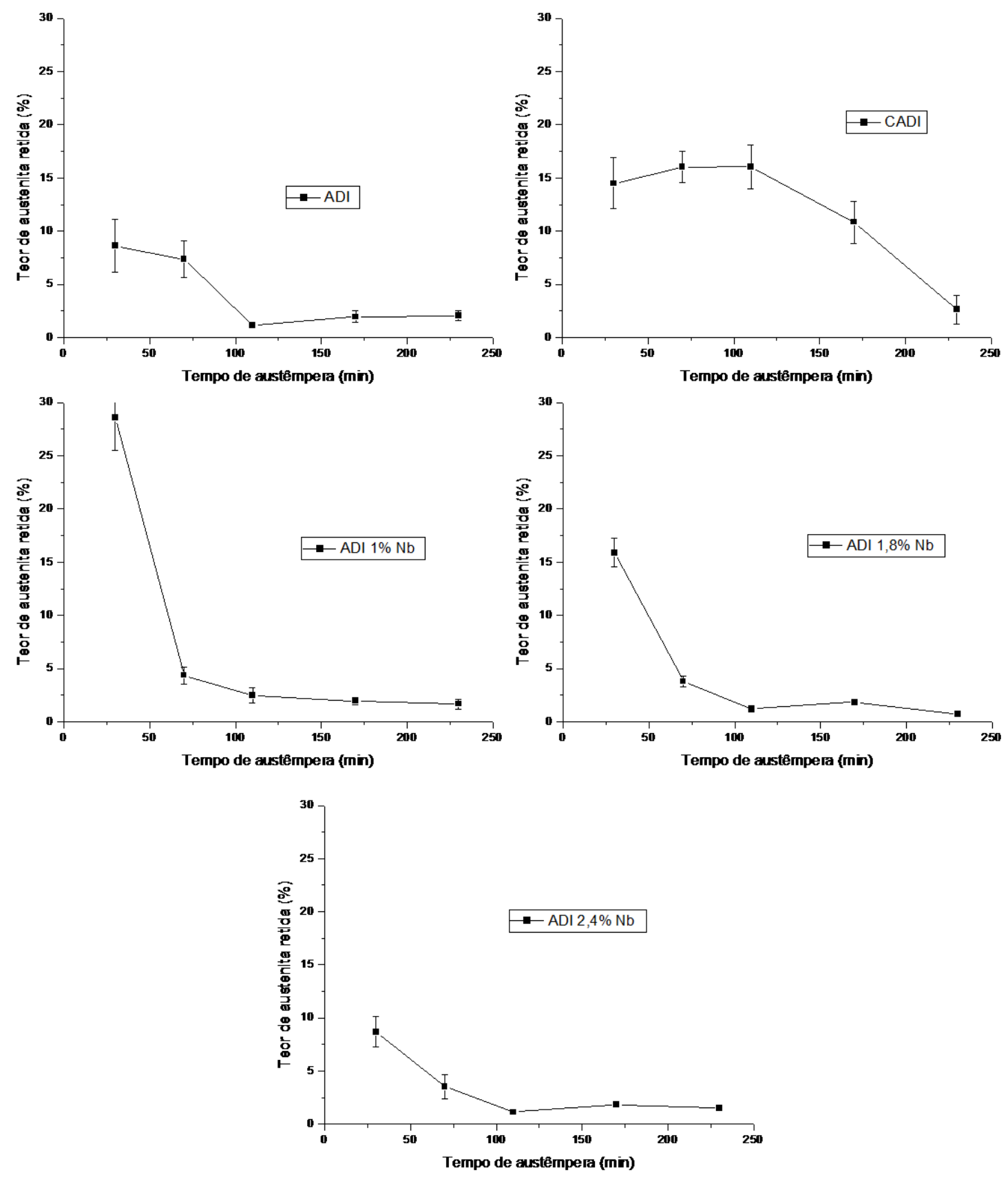

Figura 4: Teor de austenita retida na matriz ausferrítica por tempo de austêmpera para ferro nodular austemperado de diversas composições, austêmpera realizada a $270^{\circ} \mathrm{C}$, medição realizada por microscopia ótica.

A 30 minutos de austêmpera a $270^{\circ} \mathrm{C}$ notam-se diferentes morfologias de ausferrita para os diferentes materiais, Figura 5. Para ADI e CADI, observam-se microestruturas muito similares. Já para ADI com nióbio, nota-se ausferrita menos refinada, especialmente para a composição com $1 \% \mathrm{Nb}$, apresentando certa ramificação. As ripas de ausferrita tornam-se menos espessas assim que o teor de nióbio aumenta. A microestrutura menos refinada justificaria o alto teor de austenita retida observado para a amostra com 1\% de nióbio.

Seria esperada, a pequenos tempos de austêmpera, a observação de martensita formada a partir da austenita não transformada, ou seja, de baixo carbono. De fato, foram encontradas algumas poucas regiões de microestrutura distinta, tanto para ADI como ADI com adições, as quais foram identificadas como martensita. A Figura 6 mostra microestrutura martensítica identificada, figura (a), e microestrutura ausferrítica, figura (b), em ADI com $2,4 \% \mathrm{Nb}$. 

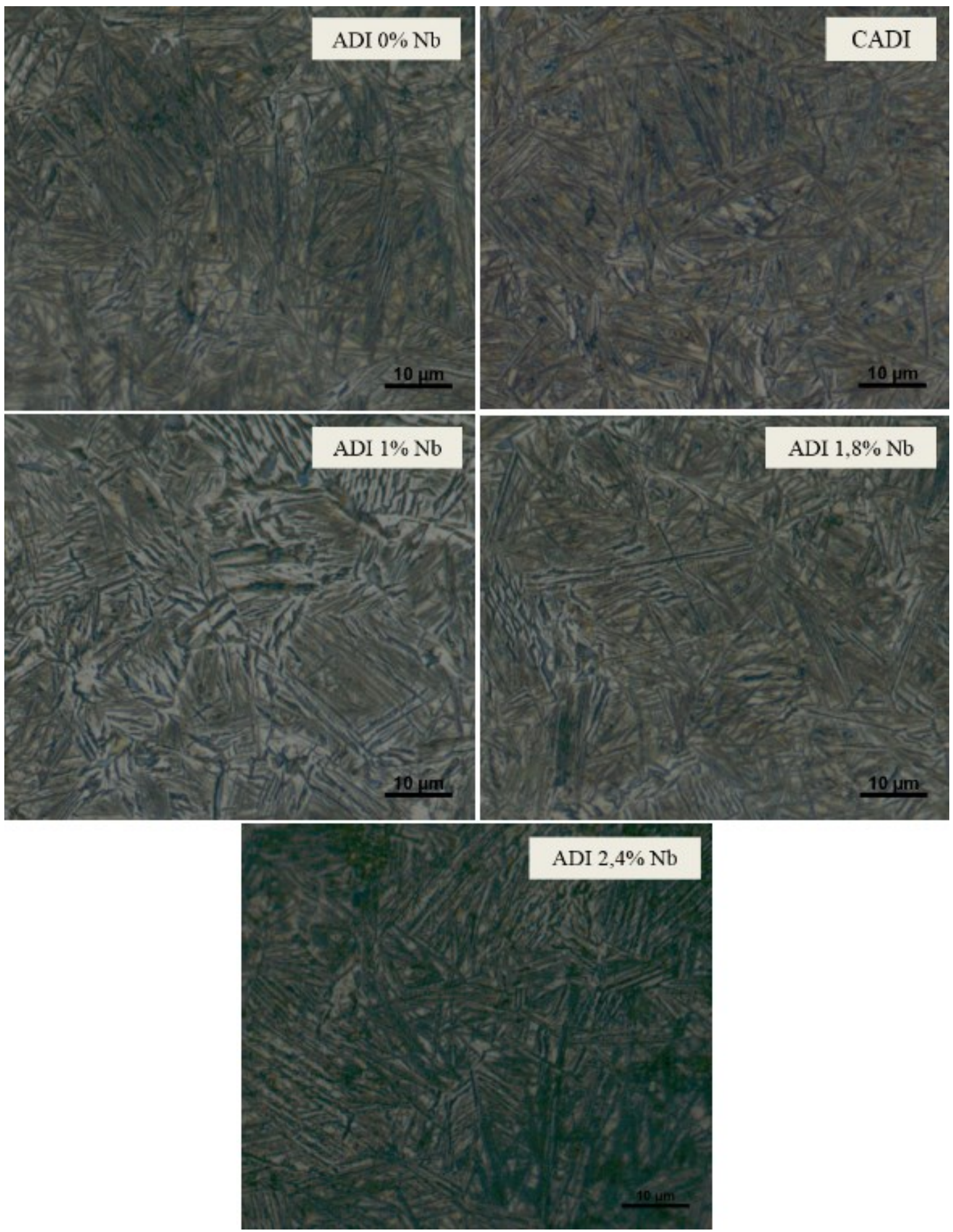

Figura 5: Microestrutura ausferrítica de ferros nodulares austemperados a $270^{\circ} \mathrm{C}$ por $30 \mathrm{~min}$. 

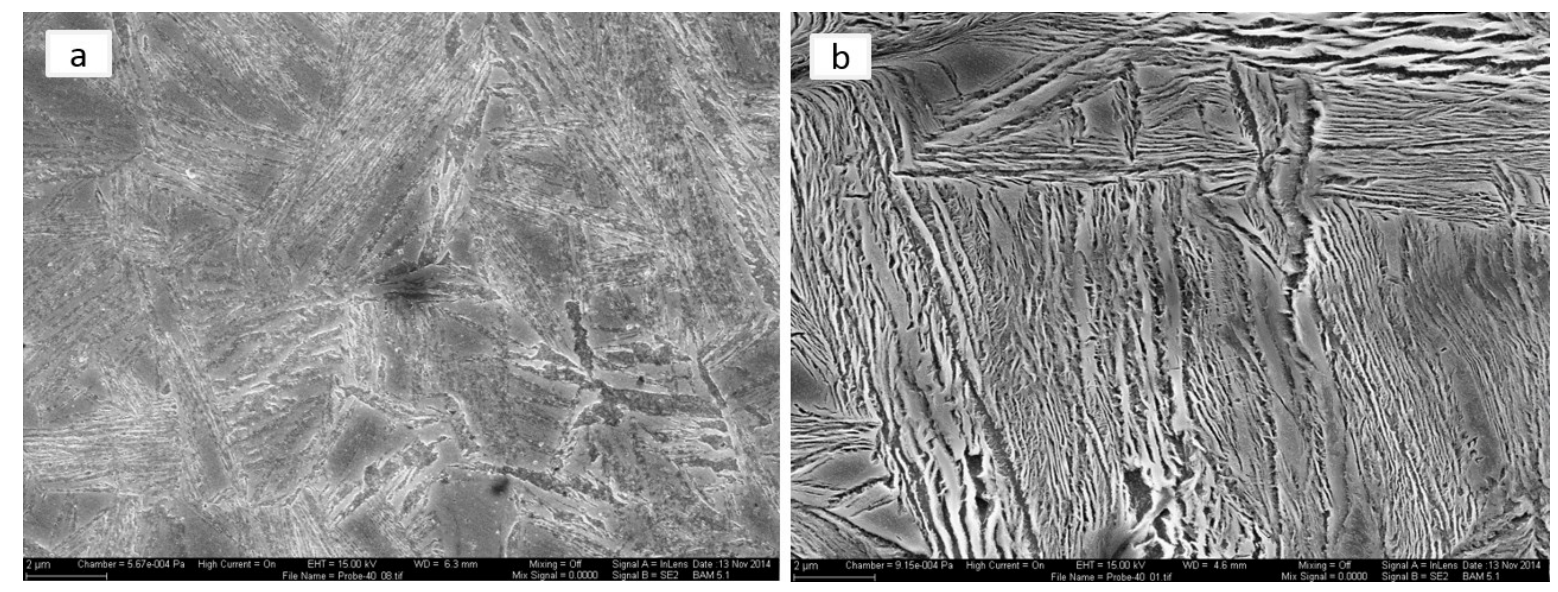

Figura 6: ADI com $2,4 \%$ de nióbio austemperado a $270^{\circ} \mathrm{C}$ por 30 minutos, microestrutura martensítica (figura a), e ausferrítica (figura b), microscopia eletrônica.

Na Figura 7 são apresentadas as microestruturas desenvolvidas pelas amostras após 110 minutos de tratamento. Para esta análise, verificam-se os maiores valores de austenita retida para as amostras com CADI, como também se infere pelas imagens da microestrutura. Para o material com cromo observa-se certa heterogeneidade para a microestrutura ausferrítica. Identificam-se pacotes de agulhas extremamente pequenas de ferrita alternadas por pacotes de longas ripas de ferrita. O tamanho das agulhas de ferrita acompanha o tamanho dos grãos de austenita. Assim sendo, houve grande heterogeneidade no tratamento de austêmpera do material com CADI, certamente provocada pela presença dos carbonetos na microestrutura. Pois a segregação de cromo para as regiões intercelulares altera a temperatura de austenitização nas microrregiões do material, resultando em diferentes tamanhos de grãos de austenita. Distintamente às micrografias a 30 minutos de austêmpera, a ausferrita para materiais com nióbio apresenta-se mais refinada, exceto para ADI $1 \% \mathrm{Nb}$ para o qual ainda se observam ripas longas e espessas de ferrita. 

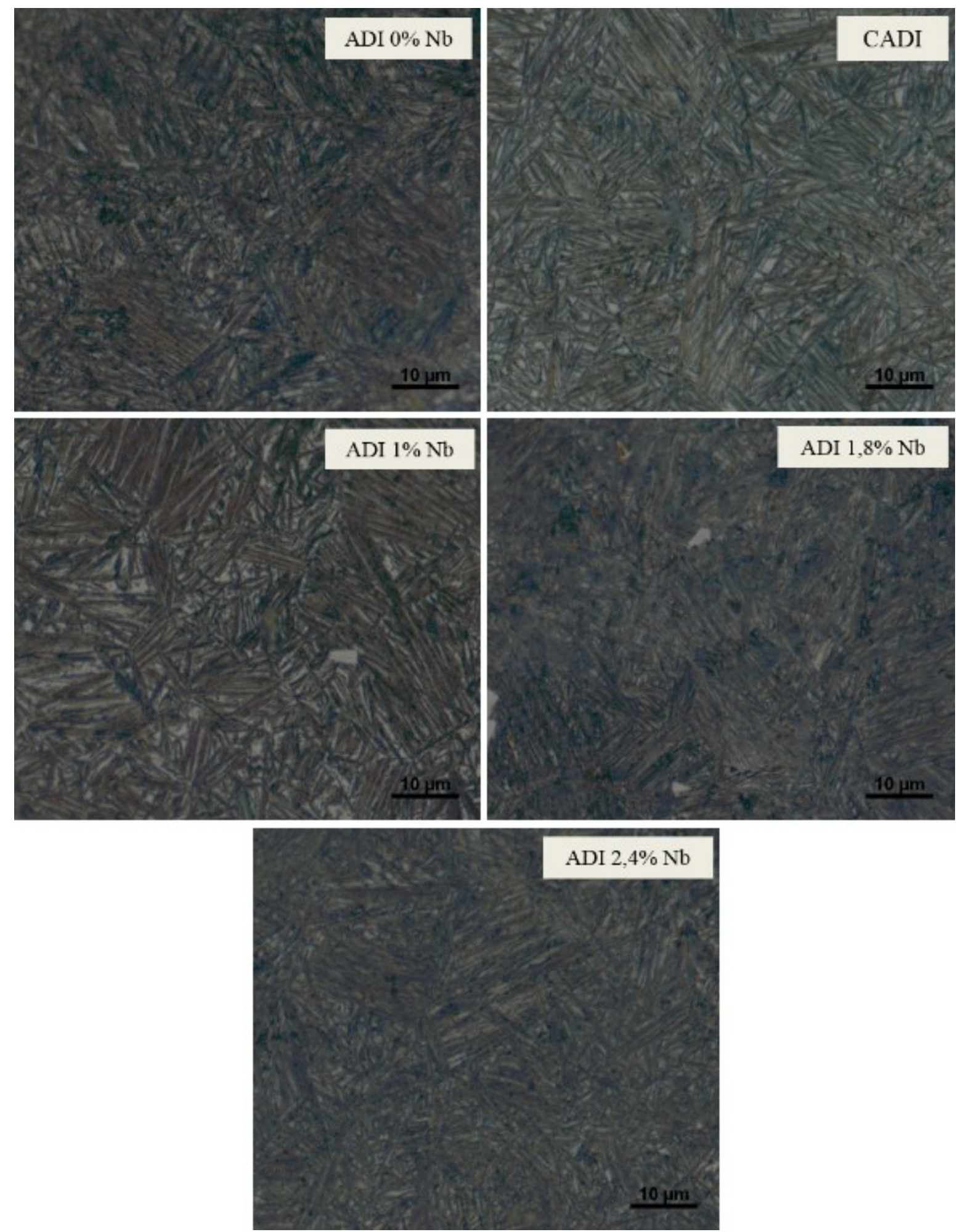

Figura 7: Microestrutura ausferrítica de ferros nodulares austemperados a $270^{\circ} \mathrm{C}$ por1 $10 \mathrm{~min}$.

Na Figura 8, observa-se que as amostras austemperadas a $310^{\circ} \mathrm{C}$ apresentaram maior quantidade de austenita retida do que as amostras austemperadas a $270^{\circ} \mathrm{C}$. Este comportamento já seria esperado, pois à mais baixa temperatura, a taxa de difusão de carbono das ripas de ferrita para a austenita que a envolve é mais baixa, resultando em formação de menor quantidade de austenita de alto carbono. Os maiores valores de teor de austenita retida são encontrados após 110 minutos de tratamento. Excepcionalmente para o CADI, observa-se alto teor de austenita para todos os tempos de austêmpera, o que se deve à redução da temperatura de início de transformação martensítica e ausferrítica para o material provocada pela presença do elemento. A 
evolução de teor de austenita para as amostras com nióbio, exceto ADI 2,4\% Nb, mostra-se similar aos resultados para o ADI sem nióbio. Porém, observa-se mais alto teor de austenita retida para ADI com nióbio do que para $\mathrm{ADI}$ sem nióbio para tempos maiores do que 110 minutos.
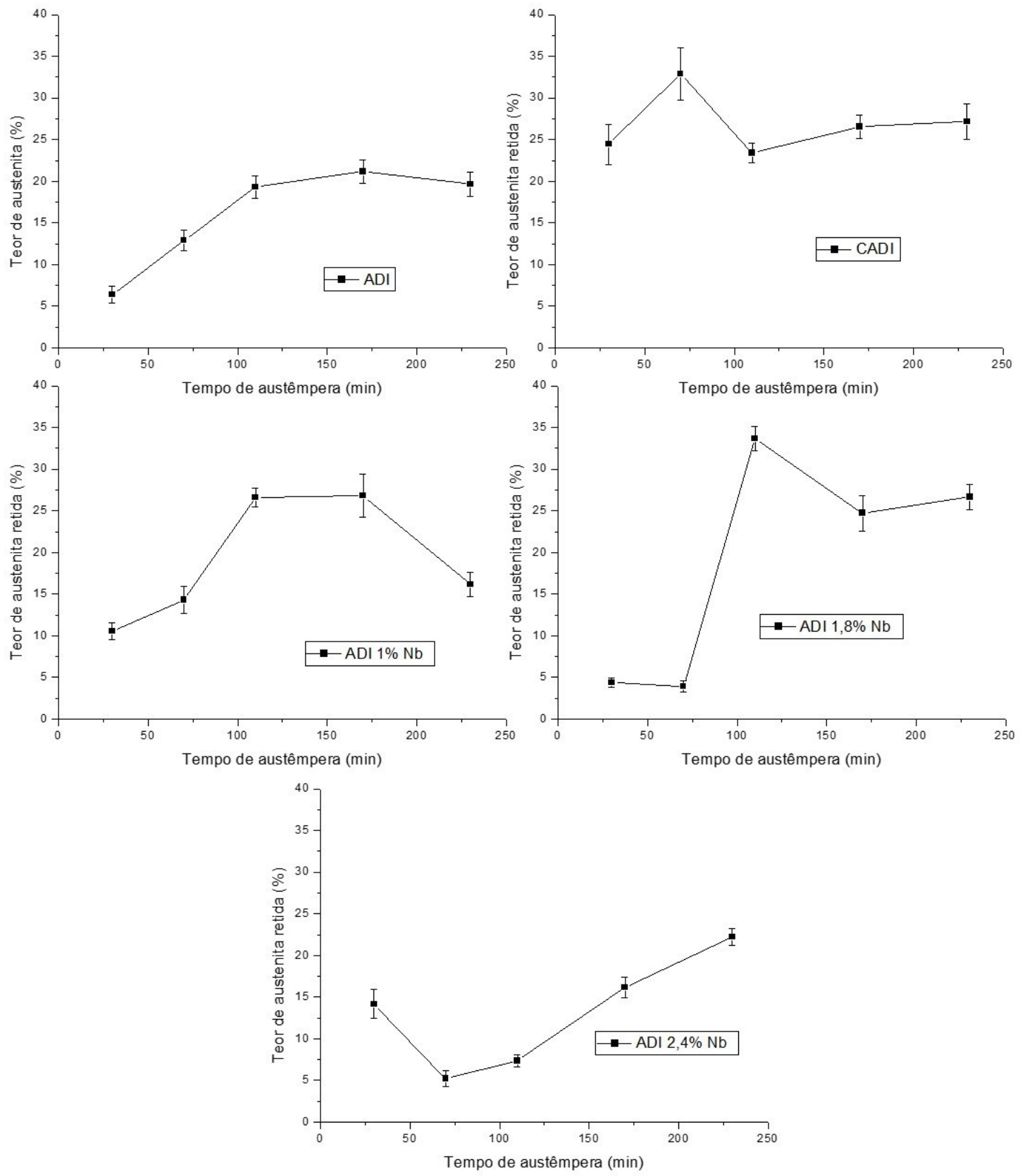

Figura 8: Teor de austenita retida na matriz ausferrítica por tempo de austêmpera para ferro nodular austemperado de diversas composições, austêmpera realizada a $310^{\circ} \mathrm{C}$, edição realizada por microscopia ótica.

As micrografias das microestruturas austemperadas a $310^{\circ} \mathrm{C}$ por 30 minutos são mostradas na Figura 9. É possível notar a microestrutura menos refinada para o tratamento a $310^{\circ} \mathrm{C}$ do que para o tratamento a $270^{\circ} \mathrm{C}$. Observa-se para os materiais com nióbio, microestrutura com ripas de ferrita mais curtas e mais delgadas. Tal tendência acompanha as adições de nióbio. Embora a distinção de microestrutura seja grande em relação ao ADI, a amostra de ADI com 1,8\% Nb apresenta teor de austenita próximo ao de ADI após 30 minutos de austêmpera. Para o CADI, são encontradas longas ripas de ferrita em formato de plumagem. 

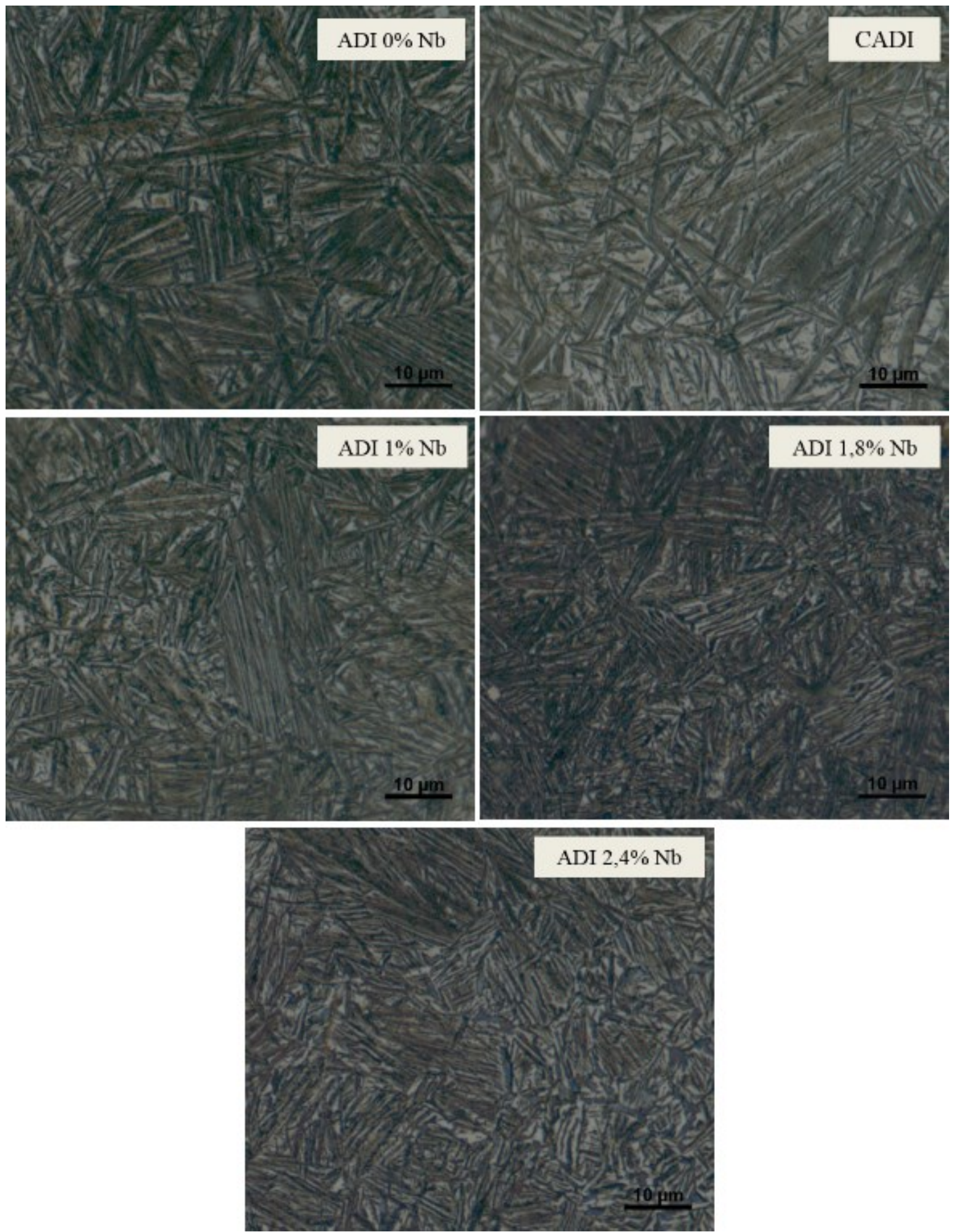

Figura 9: Microestrutura ausferrítica de ferros nodulares austemperados a $310^{\circ} \mathrm{C}$ por $30 \mathrm{~min}$

A 110 minutos de austêmpera sucede o pico de austenita retida para três materiais, a saber, ADI, ADI $1 \% \mathrm{Nb}$ e ADI $1,8 \% \mathrm{Nb}$. De fato, microestrutura menos refinada é observada para a maior parte dos materiais, exceto para ADI $2,4 \% \mathrm{Nb}$, para o qual se observa estrutura bastante refinada e distinta, Figura 10. Este resultado vem ao encontro das medições de teor de austenita retida para esta liga, uma vez que evolução distinta de austenita é observada para ADI $2,4 \% \mathrm{Nb}$. Para o CADI, o teor de austenita medido a este tempo é um dos menores medidos para a liga a $310^{\circ} \mathrm{C}$. Observa-se a heterogeneidade do tamanho de ripas de ferrita para o 
material, de forma que se encontram longas ripas de ferrita com aspecto de plumagem em meio a pacotes de ripas de ferrita curtas e delgadas.
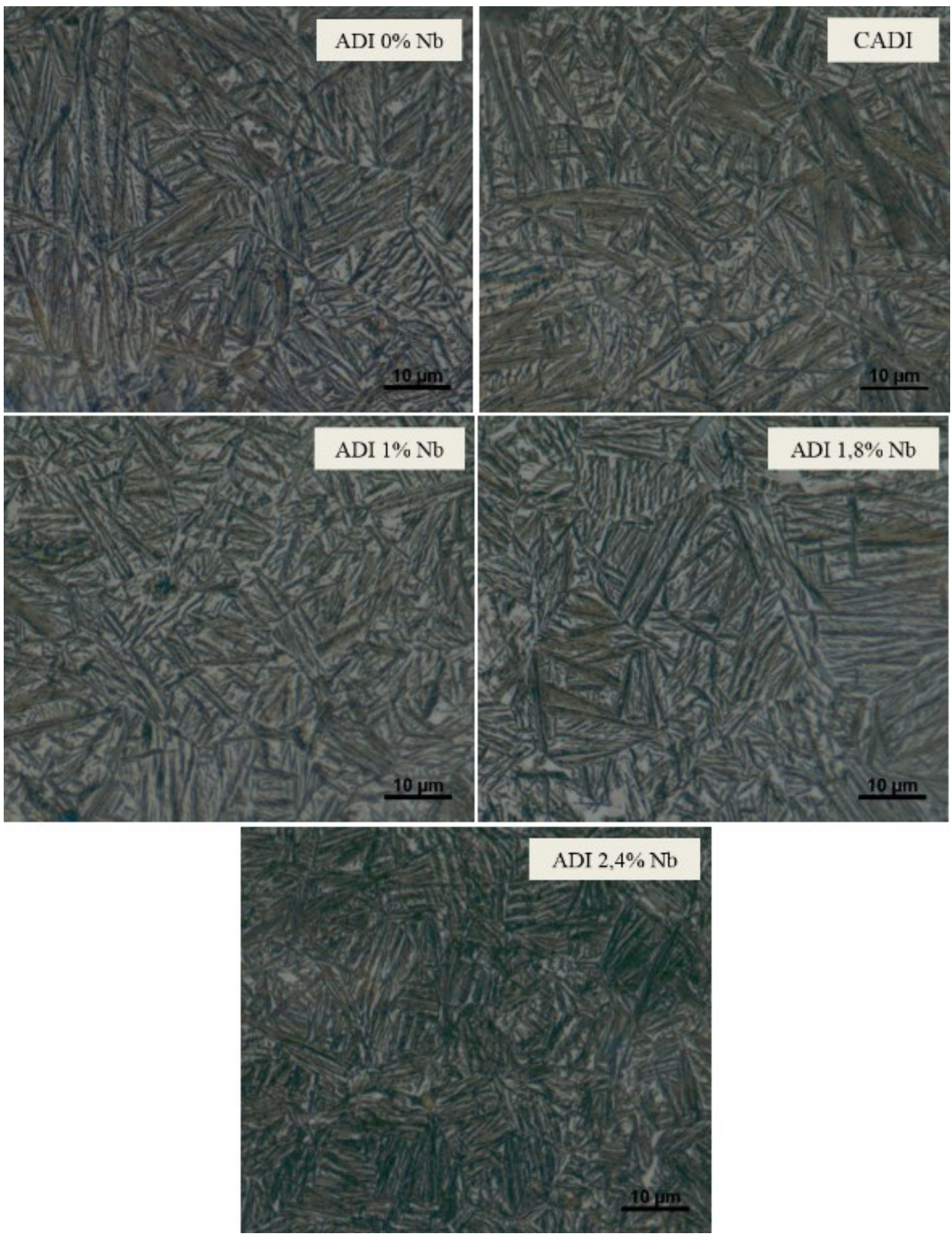

Figura 10: Microestrutura ausferrítica de ferros nodulares austemperados a $310^{\circ} \mathrm{C}$ por $110 \mathrm{~min}$. 


\section{DISCUSSÃO}

A adição de cromo e de nióbio provoca a formação de carbonetos distintos. Os carbonetos de nióbio são primários, poligonais e menores do que os carbonetos de cromo. Como são a primeira fase a se solidificar, pela baixa solubilidade de nióbio no ferro, sua distribuição é mais homogênea do que a distribuição dos carbonetos de ferro nodular com cromo. Estes, por sua vez, são carbonetos eutéticos e são formados nos contornos das células eutéticas, são de maior dimensão do que os carbonetos de nióbio e apresentam padrão dendrítico. Já seria esperado que as regiões intercelulares apresentassem teores diferentes de austenita retida pela segregação de elementos como $\mathrm{Mn}$ e Cr, que atrasam a reação do estágio I de austêmpera. Ainda deve ser conferida maior dureza para as mesmas regiões pela presença dos carbonetos em ferro fundido nodular com $1 \%$ de cromo. Assim sendo, os carbonetos $\mathrm{M}_{3} \mathrm{C}$ incrementam a heterogeneidade entre as regiões das células eutéticas.

A análise de áreas percentuais de carbonetos mostrou que o cromo apresenta maior eficiência na formação de carbonetos do que o nióbio. A adição de cromo provocou área percentual 4,5 vezes maior que a adição de nióbio de mesmo teor na liga (1\%). O aumento na área percentual de carbonetos de nióbio, assim que o nióbio é adicionado, apresenta certa linearidade.

A adição de nióbio no ferro nodular não altera os parâmetros de tratamento térmico significativamente. Para todos os primeiros tempos de austêmpera, tanto a $270^{\circ}$ como a $310^{\circ} \mathrm{C}$, certa elevação é observada para o teor de austenita retida. Existe uma peculiaridade acerca da amostra com $2,4 \% \mathrm{Nb}$, pois sua microestrutura apresenta-se em extremo refinada, mesmo a $310^{\circ} \mathrm{C}$ e 110 minutos de austêmpera, quando os demais materiais revelaram alto teor de austenita. Possivelmente a adição de nióbio, que é bastante alta para a liga, venha a alterar a Janela de Processo para a temperatura de $310^{\circ} \mathrm{C}$. Certa variação na morfologia de ausferrita com adição de nióbio é observada, diferindo do formato de finas agulhas ou ripas e revelando certa ramificação das ripas, como é típico de microestrutura resultante de tratamento de austêmpera a maior temperatura.

Quanto à adição de cromo, observa-se distinção maior em relação ao ADI sem adições. Encontrou-se maior teor de austenita retida para os tratamentos a ambas temperaturas. O elemento reduz a temperatura de início de transformação martensítica e certamente ausferrítica, incrementando a quantidade de austenita retida. Certo atraso da Janela de Processo é observado a $270^{\circ} \mathrm{C}$ de austêmpera para o CADI. Observou-se microestrutura ausferrítica mais heterogênea, provavelmente devido à maior segregação presente no material, que promove o adiantamento de austenitização nas regiões intercelulares, ricas em cromo e o consequente atraso na reação do estágio I.

Observa-se que, para quase todas as composições, encontram-se picos de austenita a tempos menores à menor temperatura $\left(270^{\circ} \mathrm{C}\right)$. Tal tendência é justificada pela maior taxa de nucleação de ripas de ferrita para menores temperaturas [20]. Sabe-se que o efeito de cromo é o de reduzir a temperatura início de transformação. Portanto, é esperado que a reação de estágio I seja atrasada para o CADI, como de fato ocorreu para a temperatura de $270^{\circ} \mathrm{C}$. Para o tratamento a $310^{\circ} \mathrm{C}$, nota-se um pico a 70 minutos e novamente outra elevação a maiores tempos para o CADI, de forma que os teores de austenita são altos para todos os tempos para o material, não podendo ser estimado o período de Janela de Processo.

\section{CONCLUSÕES}

Quando se adiciona nióbio a ferro fundido nodular, formam-se carbonetos primários e poligonais, de forma que, quanto maior a adição de nióbio, maior a fração volumétrica de carbonetos de nióbio. A adição de cromo resulta na formação de carbonetos de padrão dendrítico e segregados em regiões intercelulares. A adição de cromo em ferro fundido nodular resulta na formação de maior fração volumétrica de carbonetos do que a mesma adição (1\%) de nióbio e até de adições maiores de nióbio (1,8 e 2,4\%).

Adições de nióbio de até 2,4\% resultam em microestrutura ausferrítica com ramificações. Observam-se microestruturas mais refinadas com adições crescentes de nióbio. São obtidos maiores valores de teor de austenita retida para ADI com nióbio do que para ADI. Já a adição de cromo de 1\% aumenta significativamente o teor de austenita retida estimado por metalografia, pelo efeito do cromo de redução de temperatura Ms. Microestrutura ausferrítica mais heterogênea confere-se para CADI.

\section{AGRADECIMENTOS}

Os autores agradecem à Capes pelo apoio financeiro, à Tupy S.A. pela produção de amostras e disponibilização de laboratórios, a Jair Petry pelo tratamento térmico das amostras e a Romeo Saliwan pelas imagens em microscopia eletrônica. 


\section{BIBLIOGRAFIA}

[1] HAYRYNEN, L. K., BRANDENBERG, K. R., “Carbidic Austempered Ductile Iron (CADI) - The New Wear Material”, Transactions of the American Foundry Society, v. 111, n.3-088, pp. 845-850, 2002.

[2] FULLER A. G., “Austempered Ductile Irons - Present Applications”, Materials \& Design, v. 6, n. 3, 1985.

[3] LAINO, S., SIKORA, J., DOMMARCO R., "Wear Behavior of CADI Operating Under Different Tribosystems", ISIJ International, v. 50, n.3, pp. 418-424, Dez. 2009.

[4] VATAVUK, J., VILLAR, C. A., "Ferro Fundido Nodular com Nióbio para Aumento de Resistência ao Desgaste em Anéis de Pistão de Motores de Combustão Interna", Revista Mackenzie de Engenharia e Computação, ano 3, n. 03, pp. 71-85, 2002.

[5] SILVA, R. C. S. C., TAKANO, C., GUIMARÃES, J. R. C., et al., Aspectos fundamentais da dissolução do ferro-nióbio no ferro fundido“, Fundição e Serviços, pp. 46-58, Nov., 2008.

[6] FALLON, M. J., "The effect of niobium on the structure and properties of as-cast ferritic nodular (SG) iron.", BCIRA, v. 32, n. 4, Jul. 1984.

[7] SOUZA, T. N. F., Produção e caracterização física e mecânica de ferros fundidos nodulares e ferros fundidos nodulares austemperados com adição de Nióbio., Tese de D.Sc., UFMG, Belo Horizonte, MG, Brasil, 2012.

[8] NYLÉN, T. "Niobium in Cast Iron", in: Proceedings of the International Symposium "Niobium Science and Technology”, pp. 1063-1080, Orlando, TMS, 2001, ISBN 0-9712068-0-5.

[9] GUEDES, L. C. Fragilização por fósforo de ferros fundidos nodulares austemperados, Tese de D.Sc., EPUSP, São Paulo, São Paulo, 1996.

[10] GUEDES, L. C. “Aperfeiçoamento em Ferro Fundido Resistente ao Desgaste”, Patente PI 9000218-0, República Federativa do Brasil, 1991.

[11] LUSSOLI, R. J., Efeito da adição de cobre e da seção da peça sobre as características microestruturais e mecânicas de ferro fundido nodular austemperado, Tese de D. Sc., UFSC, Florianópolis, SC, 2003.

[12] BALZER, M.C., Determinação da Janela de Processo de austêmpera de um ADI sem adição de elementos de liga através de ensaios mecânicos e metalográficos, Tese de D. Sc., UFSC, Florianópolis, 2003.

[13] BENAM, A. S., "Effect of alloying elements in austempered ductile iron (ADI) properties and its process: Review", China Foundry, v.12, n.1, Jan., 2015.

[14] ABDULLAH, B., ALIAS, S. K., JAFFAR, A., et al., "Tensile Strength Properties of Niobium Alloyed Austempered Ductile Iron on different austempering times", Advanced Materials Research, v. 457-458, pp. 1155-1158, 2012.

[15] PADAN, D. S., "Microalloying in Austempered Ductile Iron", in: AFS Proceedings, American Foundry Society, paper 12-019, pp.1-12, Shaumburg, EUA, 2012.

[16] GERVAL, V., LACAZE, J., “Critical Temperature Range in Spheroidal Graphite Cast Iron”, ISIJ International, v. 40, n.4, pp. 386-392, 2000.

[17] VOIGT, R.C., LOPER, C. R. Jr., “Austempered Ductile Iron- Process Control and Quality Assurance”, J. Heat Treating, v.3, n. 4, pp.291-309, Dez., 1984.

[18] LIU, C., ZHAO Z., "A new empirical formula for the calculation of MS temperatures in pure iron and super-low carbon alloy steels”, Journal of Materials Processing Technology, v.113, n.1-3, pp. 556-562, Jun., 2001.

[19]"RICHTREIHEN zur Kennzeichnung des Gefuges von Carbidischen Eisen-Kohlenstoff - Gusslegierung mit Eutektischen Anteilen P 442“, Verein Deustscher Giessereifachleute - Merkblatt, Düsseldorf, 1975.

[20] MOORE, D. J., ROUNS, T. N., RUNDMAN, K. B., "The Effect of Heat Treatment, Mechanical Deformation, and Alloying Element Additions on the Rate of Bainite Formation in Austempered Ductile Iron", J. Heat Treating, v. 4, n. 1, Jun.

[21] LARRAÑAGA, P., ASENJO, I, SERTUCHA, J., et al., Effect of antimony on the eutectic reaction of heavy section spheroidal graphite castings., International Journal of Cast Metals Research, v. 22, n. 1-4, 2009. 